\title{
Student-made Video Projects in Engineering Technology Courses
}

\section{Dr. Rachel Mosier P.E., Oklahoma State University}

Dr. Rachel Mosier is an Assistant Professor at Oklahoma State University. Her research interest includes sustainable infrastructure construction, engineering technology education, and technology in the classroom.

\section{Dr. William E. Genereux, Kansas State University}

William Genereux is a Professor of Computer \& Digital Media Technology at Kansas State University Polytechnic. His research interests are in media literacy and the educational use of digital media technology. He has been working with computers and technology for the past 30 years.

\section{Katie Rieger, Oklahoma State University}




\title{
Student Made Video Projects in Engineering Technology Courses
}

\begin{abstract}
Technologists are required to perform a variety of communication methods after graduation. Industry has begun producing videos as a communication method for marketing and also requiring videos as part of the employment process. Videos have become prevalent in the workplace and at home. As many students have access to video cameras in their mobile phones and access to inexpensive video-editing software, uploading videos has become a normal activity.

This research builds on previous research about YouTube videos as a student assignment. The video project incorporates the student-as-teacher approach for a research presentation. Further, the video project utilizes experiential learning to encourage students to enter new areas of social media, specifically YouTube. Instead of an in-class presentation, students were asked to create instructional videos like those they view online. The students were asked to present Engineering Technology related research topics. The research topics were in addition or to expound upon topics identified in the course.

Students not only had to communicate technical content but communicate it to a layperson in an easily understood manner. This is one of the most valuable traits of a technologist, to communicate between the theoretical/technical side to an audience with little expertise on the subject. Non-technical faculty also reviewed the videos to validate whether technology students have mastered this important communication skill. Two groups of students were given the same video project framework: construction management technology and computer technology. The combined dataset of the students will be used to determine similarities and disparities in communication, interest, and project format of the two groups.
\end{abstract}

\section{Introduction}

Technologist is not a traditional term to identify those in the work force. Engineering technology program graduates may receive a number of titles and in many states and can be licensed as a Professional Engineer (P.E.). However, the P.E. is quite important distinction in the construction industry and is frequently not a consideration elsewhere as a requirement for a title. Construction firms frequently use the title Project Engineer for unlicensed project managers. Firms employing both mechanical, electrical or civil engineers with licenses, and unlicensed construction project managers, the term engineer is saved for those having their license. This paper reviews students in a Construction (management) Engineering Technology program. For this paper, graduates of Engineering Technology Programs with 4-year degrees will be noted as technologists (IEA 2013).

Engineering Technology students and curriculum are evolving as social media becomes ever more engrained in our lives. Students are bombarded with a variety of ways to communicate including instant messages, text messages, Snapchat and YouTube while leaving the fax machine and land line behind. Further, it is appropriate to define technology here. There are two types of technology; that identified as the Engineering Technology program which graduates Technologists and that of Social Media which is used to communicate online. Engineering 
Technology students should be able to apply knowledge "to defined and applied engineering procedures, processes, systems or methodologies." Social Media however can be defined as "any technology that facilitates the dissemination and sharing of information over the Internet" (Robbins and Singer 2014). YouTube is one of many social media tools used by students, but it may not be the most prevalent. Students see YouTube as a learning tool which provides additional information (Mao 2014). College students tend to be consumers rather than producers of video media (Schmidt, 2013) and are missing out on what Daley (2003) refers to as "the language of the screen," an important piece of contemporary literacy. Although students may use social media tools frequently and with ease on their phones, they may lack more formal skills that could be translated into the workplace.

Social media tools, specifically creating videos, are technology falling under the category Technological Pedagogical Content Knowledge (TPCK) (Mishra \& Koehler 2006 and Stewart et al 2013). Traditional laboratory exercises within an Engineering Technology program can also fall within TPCK. TPCK requires the instructor to have knowledge of pedagogy, knowledge of content, and knowledge of technology. Further application of all three knowledge bases while understanding how methods of each must change to accommodate the others, like balancing on a three-legged stool (Mishra \& Koehler 2006). For clarity, the technology focus of this paper will be identified as the above defined social media tools.

The pedagogy traditionally used by this instructor is problem-based learning (PBL), where the instructor provides some content and context and has the students complete the problem. This pedagogy has been employed on previous video projects (Mosier 2016). In this case, project requirements require technical expertise in social media students would develop during their daily life. Further as a research project on construction topics, it is also an open-ended problem, where the student results are guided by their individual research and often their own preconceptions on the topic. Many of the construction research topics are approached during class, so the students have familiarity with the topic, but the research must be above and beyond course content.

This research combines two previous projects that focus on student communication specifically in utilizing videos as a presentation media. Although some similar research on student-made videos as a means of presentation has been performed, there is very little research in the field (Genereux 2017, Mosier 2016). The authors have performed much of the research on this topic. A few additional articles about using video projects in science, technology and engineering courses do exist. For example, student-made videos have been used in courses such as chemistry, (Lichter 2012) neuroscience, (Jarvinen 2012) chemical engineering, (Ludlow 2012) engineering thermodynamics, (Abulencia 2013) construction estimating, (Talley, 2013) electromagnetics, (Cheville \& Derr 2016) and biomechanics (Ebrahimi \& Higginson 2017).

The current research combines previous separate research projects into a collaborative project using a single survey instrument, adding more data points in additional students and comparing a different group of students. The initial survey was conducted on Computer Technology (ComET) students. The survey is now being conducted on Construction management Engineering Technology (CmET) students. 
There were some minor differences in the two studies. Although the CmET students have been previously exposed to projects with video interaction, these projects were optional. Therefore, not all CmET students had previously completed a video presentation. Both the instructor and the students' required Technical Writing course have offered optional video presentation projects. Since the students have been exposed to the concept and this was the first time introducing video presentations in the course, very little course time was spent explicitly on learning required techniques. This semester acts as a benchmark for the knowledge of the students on their own. Conversely, Genereux used in-class time for discussion on a variety of the video project requirements including plagiarism and video editing concepts (2014). Another difference is that the $\mathrm{CmET}$ students were still required to submit a term paper in addition to the presentation whereas the ComET video project was the sole research project in that course.

Students in the CmET program have been exposed to computer technology during various courses. They are required to take a Visual Basic programming course as well as an AutoCAD/Revit course. There are additional computer technology courses in the curriculum, which are mostly electives, so there is not an expectation that all students would have been exposed to them.

CmET students have previously been offered the opportunity to perform video presentations. The Technical Writing course which is required in their curriculum offers a video presentation option, but it is not required. Similarly, the faculty for the Business Practices course which was used as a basis for this study has offered extra credit for video presentations for many semesters and has previously written about a group of those videos (Mosier 2016). However, this is the first-time videos were a requirement as part of the course content.

\section{Methodology}

The CmET students in a Business Practice course with a research paper and presentation requirement were asked to present via video and complete a survey. The initial project information was shared with the class on the first day of the semester. A group of topics were identified for the students. Subsequently, the students chose topics the first week of September and provided rough drafts the first week of October which received peer and faculty reviews. Finally, the project was turned in the Monday of Thanksgiving week. It should be noted that the video was not peer reviewed.

The survey required students to self-assess three main topics: communication skills, student interest/engagement and project value/format using a Likert scale (Genereux 2014) shown in Table 1 . The survey questions varied slightly between the two groups as they specifically identified the name of the course and degree programs. 
Table 1 Survey Statements

\begin{tabular}{|c|}
\hline Completing the Research Project Video project has helped me to... \\
\hline Communication Skills \\
\hline $\begin{array}{l}\text { Std. Dev. } \\
\text { be more comfortable with using video editing software. }\end{array}$ \\
\hline be more comfortable with using video cameras. \\
\hline be more comfortable with publishing video online for others to see. \\
\hline consider video to be a valid form of professional communication. \\
\hline be a better communicator in my future life and career. \\
\hline Student Interest/Engagement \\
\hline $\begin{array}{l}\text { Std. Dev. } \\
\text { increase my interest in learning about the subject of construction technology. }\end{array}$ \\
\hline work hard at being knowledgeable on my topic of research. \\
\hline enjoy the Business Practices course more. \\
\hline feel like I accomplished something worthwhile. \\
\hline Project Value/Format \\
\hline $\begin{array}{l}\text { Std. Dev. } \\
\text { I recommend this project for future students. }\end{array}$ \\
\hline I had enough time to do a good job on the project. \\
\hline I was given enough information to do a good job on the project. \\
\hline My finished project represents "college level" work. \\
\hline
\end{tabular}

In addition to the self-assessment survey, the Association of American Colleges and Universities VALUE rubric was provided to students and utilized for grading. The course instructor and nontechnical faculty viewed the videos and scored the students on the rubric. The rubric identifies five different areas for assessment; organization, language, delivery, supporting material and central message. For each of these assessment areas, the minimum score of 1 represents the benchmark, scores of 2-3 are milestones with a maximum score of 4 for the capstone, indicating skill.

One difference between the ComET project and the CmET project was the amount of in class instruction on video editing techniques. The ComET project allotted course laboratory time to discuss the video portion of the project like lighting, sound, and camera angles. Another difference is the ComET project did not have a paper component (Genereux 2014). However, the CmET course did not allot any time to videography or editing techniques. Classroom discussion was limited to uploading requirements for YouTube as indicated below. Other requirements solely focused on the research paper component.

The video project requirements are as follows:

Use your research paper to create an original video essay. The length must be between 2-4 minutes, which will be part of the grade. All team members must be present and should be prepared to answer questions on their research. The videos will be shown in class, so the video quality must be acceptable for projecting. The video should be technically well executed; editing, camera angles, scene transitions, lighting, sound, composition, and pacing. The video must be uploaded and made available for public viewing on YouTube. You may publish under an anonymous pseudonym that does not identify you. (Comment section 
on your video may be turned off.) Like the paper, the video should have a clear and logical structure with an introduction, body and conclusion. The video should include a credit page which will include any citations for quotations, paraphrasing, or work in any form that you did not yourself create such as graphics, images, etc.

The videos for this project were shown to the other members of the class. Like a traditional presentation format, they were expected to take questions at the end from their classmates. Class time was also used to discuss what was and was not successful in the presentations. Issues like lighting and interference from ceiling fans were discussed.

An additional rubric was used to for grading the video portion of the project. The course faculty and an external faculty member from the Technical Writing department used the same rubric to assess the work. The Association of American Colleges and Universities developed a set of 16 rubrics for a variety of assessments including oral communication under their Valid Assessment of Learning in Undergraduate Education (VALUE) rubric initiative (AACU 2010). This rubric has been used at many institutions and allows the two faulty reviewers to have a common vocabulary for assessment.

Part of the reason to have an external faculty member review, is to have an impartial reviewer who is non-technical. This is in part due to the format of the presentation. Students were given the expectation of being able to present technical material to laypeople. After graduation they frequently present to clients and non-technical persons within their own companies.

\section{Results}

The student survey results are indicated in Table 2. The survey was presented in Likert scale where 1 indicated Strongly Disagree and 5 indicated Strongly Agree. The class had an enrollment of 45 and 30 completed the survey. It should be noted that two students did not complete the research paper project, making the total population 43 with 30 responding or approximately a $70 \%$ response rate.

Table 2 Survey Results

\begin{tabular}{|c|c|c|c|c|}
\hline \multicolumn{5}{|l|}{ Completing the Research Project Video project has helped me to... } \\
\hline & CmET & $\mathrm{CmET}$ & ComET & ComET \\
\hline Communication Skills & Mean & Std. Dev. & Mean & Std. Dev. \\
\hline be more comfortable with using video editing software. & 3.27 & 1.20 & 3.52 & 1.05 \\
\hline be more comfortable with using video cameras. & 3.03 & 1.16 & 2.78 & 1.19 \\
\hline be more comfortable with publishing video online for others to see. & 3.53 & 1.07 & 3.22 & 1.01 \\
\hline consider video to be a valid form of professional communication. & 3.63 & 0.76 & 3.41 & 1.08 \\
\hline be a better communicator in my future life and career. & 3.53 & 0.82 & 3.15 & 1.03 \\
\hline \multicolumn{5}{|l|}{ Student Interest/Engagement } \\
\hline increase my interest in learning about the subject of construction technology. & 3.26 & 1.17 & 3.07 & 1.14 \\
\hline work hard at being knowledgeable on my topic of research. & 3.60 & 1.07 & 3.52 & 0.98 \\
\hline enjoy the Business Practices course more. & 2.97 & 1.16 & 3.23 & 1.18 \\
\hline feel like I accomplished something worthwhile. & 3.23 & 1.19 & 3.44 & 1.25 \\
\hline \multicolumn{5}{|l|}{ Project Value/Format } \\
\hline I recommend this project for future students. & 3.00 & 1.23 & 3.41 & 1.19 \\
\hline I had enough time to do a good job on the project. & 4.03 & 0.72 & 4.04 & 1.09 \\
\hline I was given enough information to do a good job on the project. & 3.80 & 0.80 & 4.00 & 0.88 \\
\hline My finished project represents "college level" work. & 3.73 & 1.05 & 3.81 & 0.83 \\
\hline
\end{tabular}


Although most students agreed with the survey statements, there is an interesting result. To the items "Completing the research project, Video project, has helped me to...enjoy the Business Practices course more," the answer leans toward neutral or disagree. The students did not feel like the video project increased course enjoyment. This does match comments received after previous extra credit video assignments. Unsolicited student comments indicated that they would prefer to have options other than video assignments.

However, a strong positive response was shown for the statement "...I had enough time to do a good job on the project," indicating those who did not enjoy the project or course still recognized having the whole semester to work on the project was plenty of time. The other two statements which elicited a neutral response were "Completing the research project, Video project, has helped me to...be more comfortable using video cameras" and "...I recommend this project for future students." The two student groups did not appear to have the same attitude towards recommending the project for future students. The ComET students have a more positive response than the CmET students.

The data shows CmET students in general agree videos are a valid form of professional communication. Students are more neutral about recommending this project to future students. There is enough of a separation here to ask why students are neutral about promoting a valid project to other students. The responses between the two questions are graphed in Figure 1 indicating students who showed more positive responses the valid form of communication, the more positive the response to recommending the project. For students who did not consider the video to be a valid form of communication with neutral or negative responses, also had neutral to negative responses to recommending the project.

Figure 1

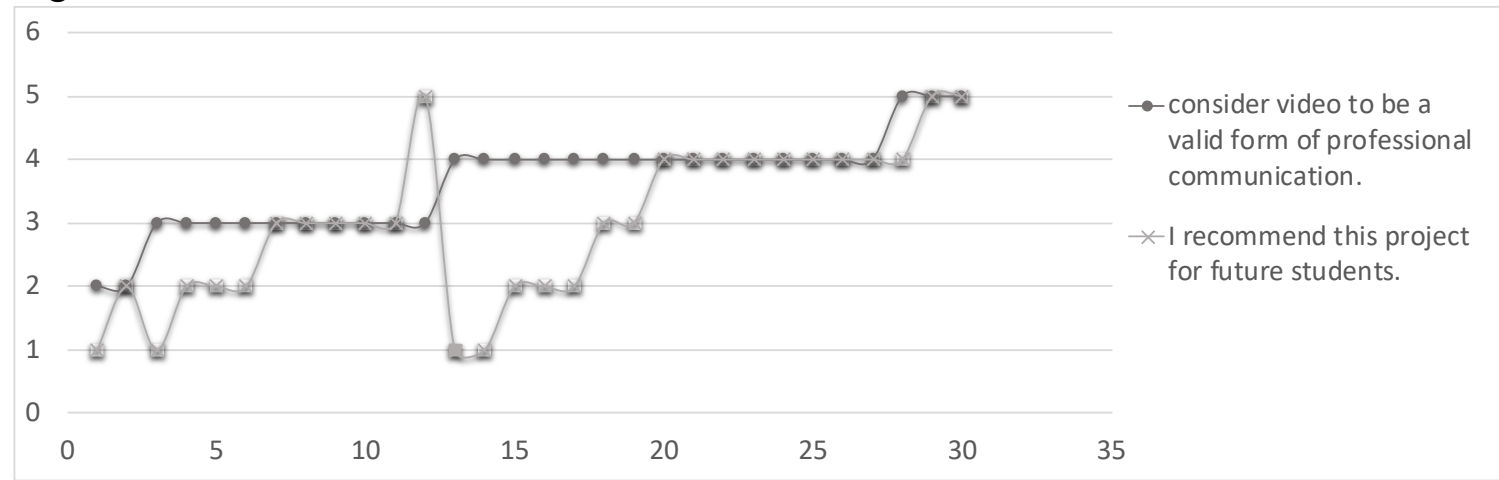

When comparing the results to the previous study, both sets of students agree that the assignment did not make them feel more comfortable with video cameras. For the CmET group, it is likely due to the options used for their videography. The CmET submitted videos taken with mobile phones which came across as quite shaky. Other students chose to use computer web cameras to create videos which caused some unusual perspective issues. These issues were discussed after the in-class presentations of the videos.

As a basis for comparison, the two statements which identified the name of the course and degree program were normalized. Those statements reflect the individual programs but are written in the same format for responses. When comparing the results of this survey to the 
previous survey on ComET students, they had similar neutral results to the video camera statement. There was a similar negative response to the course enjoyment statement between the two groups. A third similarity is that the ComET students had positive responses to the remainder of the questions as did the CmET students. An additional item of note is that although there were some differences in the project, the overall student survey responses were very similar.

The VALUE rubric assessments from the two faculty were similar, but not the same. As the two faculty reviewers have different backgrounds, it is expected that the assessments would be different. The rubric assessment used was created for oral presentations. The assessment categories do not precisely represent a video presentation. The assessment responses are indicated in Table 3.

Table 3 - VALUE Rubric Assessment

\begin{tabular}{|l|r|r|l|r|r|l|r|r|}
\hline Faculty Review & Mean & Std. Dev. & External Review & Mean & Std. Dev. & Average Review & Mean & Std. Dev. \\
\hline Organization & 3.97 & 0.13 & Organization & 2.88 & 0.81 & Organization & 3.42 & 0.43 \\
\hline Language & 3.06 & 0.25 & Language & 3.00 & 0.00 & Language & 3.03 & 0.13 \\
\hline Delivery & 3.19 & 0.36 & Delivery & 2.81 & 0.66 & Delivery & 3.00 & 0.42 \\
\hline Supporting Material & 3.36 & 0.59 & Supporting Material & 2.94 & 0.68 & Supporting Material & 3.15 & 0.49 \\
\hline Central Message & 3.47 & 0.50 & Central Message & 3.38 & 0.50 & Central Message & 3.42 & 0.44 \\
\hline
\end{tabular}

The reviews indicate that the Organization and Central Message were good. The terms may be obvious, however worth defining here. Organizational pattern should be clearly and consistently observable. The Central Message should be obvious through repetition, identification and support (AACU 2010). Language and Delivery were not as good. These terms may be obvious but require definition. Language choices should be imaginative, memorable and audience appropriate. Delivery techniques for an oral presentation should include eye contact, gestures and vocal expressiveness (AACU 2010). Some of the students chose to provide a voiceover for a slide presentation on video. The choice to provide a voiceover reduced the delivery scores.

\section{Instructor Perspective}

The students did not all have YouTube accounts which surprising. There was an expectation that students would be fully utilizing social media. The literature outside of Engineering Technology also supports this finding, that many students use and are familiar with Facebook and Snapchat, but less so with YouTube (Mao 2014). As previous extra credit assignments had also included video submissions, there was an additional expectation that students would be familiar and comfortable with the concept.

No CmET classroom time was taken to specifically cover topics like videography methods, editing or what constitutes a good video. This was a consideration as the ComET students do have class time for this type of discussion. Since this was a new course concept and requirement for CmET, a stepwise approach was taken. First introduce the concept of a video presentation as a requirement. Then after receiving the first round of videos, update the expectations to a higher level of rigor. This will happen in future semesters and hopefully affect the outcome. 
In the future, class time will also be allocated to video peer reviews. Currently the research is a peer reviewed paper paired with a presentation. Students did not have an opportunity to review other student work during the process. Therefore, there was not a visible benchmark for success. After having seen other presentations, the students were able to identify what constituted better or worse quality presentations during classroom discussion.

\section{Conclusion}

There is still much to understand about student attitudes towards video presentation projects. Although there is some existing research on student use of social media in the classroom (Mao 2014), YouTube continues to be one of the least used in the classroom environment. As a platform for $\mathrm{CmET}$ students, it has value after graduation. Many construction companies use videos in a variety of ways to communicate. Construction workers may take video of a project to share with clients and construction companies will use videos for marketing and recruiting purposes. For these reasons, learning how to communicate technical information via videos is vital to our students.

While CmET students were generally positive about videos are a valid form of professional communication, the students were neutral to negative about recommending this project to future students. This disparity may come from the students not utilizing YouTube as a communication device. Equally it may have to do with classroom presentation. More time will be spent on focusing on the "why?" of the project, to help students become more familiar with a variety of communication methods.

\section{References}

AACU. (2010). Written communication VALUE rubric. Washington, DC: Association of American Colleges and Universities. Retrieved from http://www.aacu.org/value/rubrics/WrittenCommunication.cfm

Abulencia, J. P., Vigeant, M. A., \& Silverstein, D. L. (2013). Using video media to enhance conceptual learning in an undergraduate thermodynamics course. In Proceedings of the 2013 American Society for Engineering Education Annual Conference \& Exposition. Atlanta, GA.

Cheville, A. \& Derr, B. H. (2016). Using videos to elicit self-explanations of emergent electromagnetic concepts. In Proceedings of the 2016 American Society for Engineering Education Annual Conference \& Exposition. New Orleans, LA.

Daley, E. (2003). Expanding the concept of literacy. Educause Review, 38(2), 33-40.

Ebrahimi, A. \& Higginson, J. (2017). Board \# 112: EEGRC Poster: Using super heroes to relay biomechanics principles in education. In Proceedings of the 2017 American Society for Engineering Education Annual Conference \& Exposition. Columbus, $\mathrm{OH}$.

Genereux, W. E. (2017). Board \# 42: Exploring video projects and media literacy in a computer networking course. In Proceedings of the 2017 American Society for Engineering Education Annual Conference \& Exposition. Columbus, OH. https://peer.asee.org/27852.

Genereux, W. E. (2014). Student made video projects in a computer technology course. In Proceedings of the 2014 American Society for Engineering Education Annual Conference \& Exposition. Indianapolis, IN. https://peer.asee.org/23063

International Engineering Alliance (IEA). (2013). Graduate Attributes and Professional Competencies. 3(21), June 2013. 
Jarvinen, M. K., Jarvinen, L. Z., \& Sheehan, D. N. (2012). Application of core science concepts using digital video: A "hands-on" laptop approach. Journal of College Science Teaching, 41(6), 16-24.

Lichter, J. (2012). Using YouTube as a platform for teaching and learning solubility rules. Journal of Chemical Education, 89(9), 1133-1137.

Ludlow, D. K. (2012). Using student-produced videos to enhance learning engagement in a chemical engineering thermodynamics course. In Proceedings of the American Institute of Chemical Engineers 2012 Annual Meeting. New York, NY: American Institute of Chemical Engineers.

Mao, J. (2014.) Social media for learning: A mixed methods study on high school students' technology affordances and perspectives. Computers in Human Behavior, Vol.33, pp.213223.

Mishra, P., \& Koehler, M. (2006). Technological pedagogical content knowledge: A framework for teacher knowledge. Teachers College Record, 108(6), 1017-1054.

Mosier, R.D. (2016). Participation in structures classes via student made videos. In Proceedings of the 2016 American Society for Engineering Education Annual Conference \& Exposition. Columbus, OH. doi: 10.18260/p.25859.

Robbins, S.P. and Singer, J.B. (2014). From the Editor-The medium is the message: Integrating social media and social work education. Journal of Social Work Education. 50(3): 387-390.

Schmidt, H. (2013). Media literacy education from kindergarten to college : A comparison of how media literacy is addressed across the educational system. Journal of Media Literacy Education, 5(1), 295-309.

Stewart, J., Antonenko, P., Robinson, S. and Mwavita, M. (2013). Intrapersonal Factors Affecting Technological Pedagogical Content Knowledge of Agricultural Education Teachers. Journal of Agricultural Education. 54(3), pp. 157 - 170. DOI: 10.5032/jae.2013.03157

Talley, K.G. (2013). Lights, camera, action! Peer-to-peer learning through graduate student videos. In Proceedings of the 2013 American Society for Engineering Education Annual Conference \& Exposition. Atlanta, GA. 